\title{
IWRM as a System Approach to Water Security: Evidence from the Awash River Basin of Ethiopia
}

\author{
Reta Hailu' ${ }^{1, *}$, Degefa Tolossa ${ }^{1}$, Getnet Alemu1,2 \\ 1 Centre for Rural Development, Addis Ababa University, Ethiopia; reta.hailu@aau.edu.et \\ 1 Centre for Rural Development, Addis Ababa University, Ethiopia; degefa.tolossa@aau.edu.et \\ 1,2 Institute of Development and Policy Research, Ethiopia; galemu2001@yahoo.com \\ * Correspondence: Email: reta.hailu@aau.edu.et; Tel.:+251911389735 \\ ORCID: http://orcid.org/0000-0003-2915-6407
}

\begin{abstract}
Integrated Water Resources Management (IWRM) is one of the system thinking approaches emerged in the 1990s. Since then it has been applied in various countries and contexts. However, the implementation of the IWRM is contested. There are paucity of literature and guidelines as to how the concept can be operationalized. In Ethiopia, there is no evidence that IWRM is successfully instituted. Particularly, IWRM has never been implemented in the Awash River Basin. The study generated data from household and institutional surveys, in-depth interviews, focused group discussions, workshops, and secondary sources. Multiple sources of data were triangulated and thematically summarized. We found that pragmatic water resources management through system approach helps to recognize river basin as a bigger system in which the natural and human systems function. This resolves the problem of fragmentations among among various actors, sectors, interest and priorities. That it facilitates the coordination of various subsystems. The operationalization of IWRM as a system to secure water resources require the establishment and/or strengthening of the interactions of various systems, subsystems, and the elements within the entire basin system. Finally, enabling institutional environments should be considered as a medium of realizing IWRM.
\end{abstract}

Keywords: Integrated Water Resources Management (IWRM); system thinking; water security; Awash basin; Ethiopia

\section{Introduction}

Water security is systemic and complex. Such systemic approach to water resources management has been received little attention for long-time [1, 2]. It is non-linear that need to be analyzed using systems thinking approach. In systems thinking, the whole is greater than the sum of its parts because a system is dynamic and not simply determined by the actions of an enclave sector [3]. The elements in a system are not fragmented and uncoordinated. Its essence is a holistic approach that considers pragmatic ${ }^{1}$ water resources management. Unlike reductionist view, the holistic approach allows moving beyond the prescriptions of conventional supply-side for the complex reality of water resources [4]. It accentuates water resources security as the outcome of holistic and system view of complex realities [5]. System thinking takes into account the whole interfaces and relationships [6]. In the word of [7] (p.157), system perspective in water security is "more comprehensive, and integrates planning, design, maintenance and operation of the water-related

\footnotetext{
${ }^{1}$ In the context of this study, pragmatism is a worldview of water resources management dealing with IWRM sensibly and realistically in a way that is based on practical rather than theoretical considerations.
} 
infrastructure activities in an approach to support the decision-making process based on the engineering, natural, social, and other sciences." It is a pathway of thinking, which seeks to detect and comprehend the multitude of problems, their interplays, and interdependencies to solve them. Thus, systems thinking allows thinkers to grasp the uncertainty facing water security [8]. In other words, systemic problems of water security demand systems thinking-based solutions.

One of the systems thinking emerged in the 1990s was Integrated Water Resources Management (IWRM) even though the concept traced back to the 1970s [9, 10]. IWRM was a mantra as a systemic framework to overcome water security challenges. Since then it has evolved as a conceptual framework and underpinned the intricacies of water problems and decisions [11]. It has been perceived as a means to overcome the problem of institutions, coordination, and system failures. In the developing countries, IWRM was hoped to 'increase water productivity and improve water quality' [12]. This promise drove several international organizations such as the World Bank, UNwater, World Economic Forum, Global Water Partnership (GWP), International Network of Basin Organizations (INBOs), International Water Management Institutes (IWMI), and many NGOs and agencies, practitioners, and experts. They prescribe and suggest IWRM as a process and a mechanism to mitigate the problem of water insecurity at the basin scale. IWRM also believed to facilitate policy discussions, improve water resources management practices, and support education and capacity building [13].

Furthermore, IWRM has been promoted as 'a silver bullet' to address structural and institutional crises of water resources management [14]. The mantra has attracted several developing countries to incorporate IWRM as a guiding principle for their national water policy and programs [13, 15, 12], for two major reasons. First, in the early 1990s, IWRM was hijacked by the neoliberal resources democratization process and hence donors can only channels their funds and supports through 'integrated approach'- on the contingent of up-taking IWRM. Developing countries were forced to accept IWRM to secure funding and as a means to liberalize their water resources sector. Second, various donors, NGOs, and think tanks were strongly advocating and promoting the principles of IWRM as a panacea to curb water the resources management crises in those countries. As a result, several countries have adopted IWRM in their policies and programs haphazardly without proper institutional setting that affected water resources management in various developing countries by confusing its concepts [16]. The concept of IWRM is so fuzzy that what to integrate, how, by whom, or where remain vague [9].

The successes of implementing IWRM are mixed and hence contentious [17]. It is like half-full or half-empty. The practice of IWRM in developing countries to ensure water security has the major setback $[18,19,11]$. Likewise, [20] reported that more than $80 \%$ of countries had tried to apply IWRM in their policies and strategies yet the success of the efforts are under scrutiny. To cite a few, IWRM has failed in Brazil where various barriers affected the integration of socio-economic aspects [21]. In the USA, IWRM is not penetrated deeply into the culture of water resources managers [13]. In Ghana, "there is a conflict between the IWRM goal of integrating all water uses and sectors in the management of water resources and focusing on the prioritization of water delivery services"[23] (p.33). In Ethiopia, the failure of IWRM attributed to the institutional failure and political commitment despite the policy alleged the entire water resources process is based on IWRM [15, 23]. Consistent with these experiences, [10](p.21) curiously noted "it is hard to the find any water policy, program or project at any scale anywhere in the world that can be rated a score of 30 out of 100 on a scale of 1 to 100 (1 being no integrated water resources management and 100 being full integration)."

The reasons are also context dependent but the core explanation was water resources officialdom always discursively rhetoric and overuse IWRM as a 'term of the day' without realizing its entities and tenets [9]. The water policy or bureaucratic systems widely use IWRM principles to justify water resources management as a novel idea. As a result, it becomes a normative approach fashioned in the formalization of water policy [24]. This shows the impediment in the operationalization of the concept rather than the principle itself. The setback in IWRM is not only attributed to the cumbersome of the concept, which is vastly a process-oriented but also how it could be practiced. It is in this context that new challenges need a change an approach and institutional arrangements. The change 
should translate the 'buzzy' principles to actions and the policy into realities. It must also reconcile conflicting and competing concepts and practices.

Informed by an international sphere of influences, Ethiopia has formulated water resources management policy geared towards IWRM through River Basin Organizations (RBOs) as early as 1999 [25]. It was the time when IWRM received greater attention, becoming catchy and buzzy. The fundamental principles of IWRM in Ethiopia are aimed to guide equitable, sustainable and efficient development, utilization, conservation, and protection of water resources in Ethiopia. The 1992 Dublin Principles and other international fora influenced the policy statement. The policy declared IWRM as a general framework and River Basin Organizations (RBOs) as a unit of IWRM. Water sector strategy, programs, and several laws and regulations followed the policy statements. However, as to our present knowledge, the efforts have neither instituted IWRM at the basin level nor provided any real guidance to the water professionals and practitioners as to how the concept can be operationalized. Particularly, IWRM has never been implemented in the Awash River Basin [15].

The implementation of IWRM is setback despite huge emphasis of IWRM as a remedy for water insecurity in basin context. The move towards IWRM must come up with an option. The paper seeks to answer the question how could IWRM be a roadmap to attain water security in the Awash River Basin. In order to answer this question, we need to ask two more questions. What to integrate? How to integrate? While the first question considers the sectors and actors must be brought together, the second question addresses the mechanism to link and understand various sectors, actors, and uses. The paper thus introduced systems thinking, as pragmatic IWRM, to integrate the interplay and interaction of actors and sectors in the basin. It further argues that institutional processes could be possible through system thinking. Despite, application of system thinking in various discipline, its application in water resources management is very limited. This paper is far from a comprehensive analysis of the entire variants of systems theory in water resources management. It rather introduces systems idea to understand the problem of water resources and illustrate the complex issues of IWRM in basin context.

The remaining parts of the paper are organized as follow: section two describes the conceptual framework that brings IWRM at the center of systems thinking approach. Section three describes the methods and techniques used to gather and analyze data. Section four presents the myths and existing implementation gaps in IWRM followed by section five, which outlines the system approach in water resources management of Awash Basin. The sixth section explores enabling institutional environments to put IWRM pragmatically. Finally, section seven draws key conclusions and policy implications.

\section{Conceptual Framework}

The word 'integrated' is fashioned in various disciplines in different context ${ }^{2}$. Adey et al.[15] offered a different interpretation of integration. In systems perspective, integration is an opposite of 'reductionist' approach to water resources management[4]. According to Business Dictionary ${ }^{3}$, integration is 'a process of attaining close and seamless coordination between several departments, groups, organizations, systems, etc.' This definition seems to be a relevant but discursive limit. The definition involves a process and coordination, which IWRM is all about. In the context of this study, integration is the coordination and engagement of various sectors, institutions, actors, and interest and priorities. This definition accords with 41 possible areas of integration outlined by [10]. Among several aegis of IWRM, the definition embraces key areas of water resources relevant to basin systems.

In river basin context, IWRM is defined as 'a process that enables the coordinated management of water, land and related resources within the limits of a basin so as to optimize and equitably share

2 Integrated Rural Development, Integrated Family Planning, Integrated Pest Management, Integrated Environmental Management, Integrated Forest Management, Integrated Land Use Planning, Integrated Data Management, etc.

${ }^{3}$ http://www.businessdictionary.com/definition/integration.html 
the resulting socioeconomic well-being without compromising the long-term health of vital ecosystems' $[14]$ (p.18). When objectively seen, it is full of contested terminologies. It is simply 'unusable' or 'un-implementable' in operational terms [10]. The definition also left the concept for further interpretations remarking it as a 'process'. It does not indicate how integration is possible the question that matters practically! However, the process-oriented nature of IWRM provides an avenue for water sectors and stakeholders to interact and to create dialogues for joint action and collaboration. Furthermore, IWRM embeds several sub-processes like a 'big tent' [13].

The other undeniable fact is that the IWRM often donor-driven or via NGOs interventions whereas the government stakeholders are approaching sectorial modalities. These external pushes sometimes regularly meet as platforms to discuss on water issues. Information shared in these platforms does not always translate into coordinated donor efforts [11]. Thus, understanding the underlying causes of such narrow focus is the central concern of systems thinking from the lens of IWRM. The recognition of IWRM as a system approach to water without appreciating the complexity in terms of the concept, scale [26], and institutional setting is a futile exercise. The integration of sectors and power structures are becoming problematic.

To this end, the means to achieve water security must go beyond the conventional assumption of 'unfinished' concepts of IWRM. Amma \& Gupta [22] underlined that the holistic and sectorial focused approaches in water service delivery seem to be irreconcilable. Such sectorial thinking must shift to systems thinking through IWRM called pragmatic viewpoint. It exploits the strengths of the IWRM principles because pragmatism is an attempt to coordinate and integrate realistically the social system, human system, equity aspect, and political system [7]. A system approach is almost absent from discussion of water resources management at the basin level. Within the context of the larger system, the basin is the larger system while the aquifers and surface water are subsystems. This is how the paper employed a holistic framework that can accommodate emerging issues of water resources security (Figure 1).

One cannot devoid the principles of IWRM because they are demanding in context where the coordination is needed between resources -land and water, as well as among stakeholders on equitable resources access. Ruther weakness could be bridged in the sense that IWRM can induce dialogues to sustain the return from the basin. Scientific community believe that the IWRM is emerged from system approaches that transposed integrated management into water resources [16].Thus, action-oriented arrangements to implement the principles and frameworks of IWRM are needed. The working definition of IWRM can be provided from systems perspective. Integration requires the inclusion and coordination of different systems at various levels-micro, meso, and macro ${ }^{4}$

\footnotetext{
${ }^{4}$ A macro-level system deals with part of a geographical zone, such as a river, lake or aquifer basin. A mesolevel system deals with a regional or local ecological system of a lake, river valley within a basin, or sub-aquifer within an aquifer province. A micro-level system deals with a relatively uniform ecological and hydrological [14](p.22).
} 


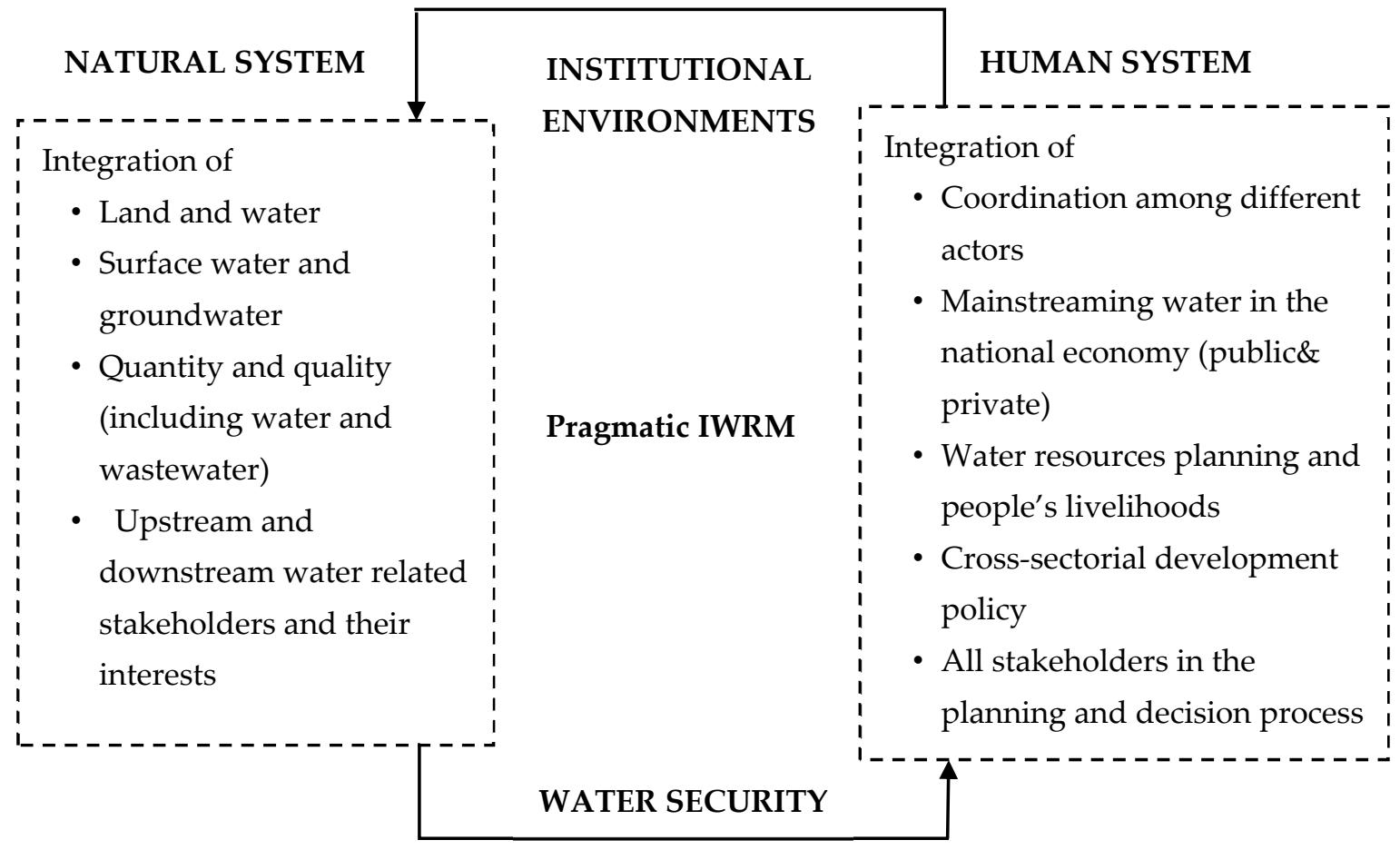

Figure 1. Conceptual framework to underpin IWRM pragmatically from systems perspective to attain water security (Source: Elaborated based on[27]

According to [27], the integration involves natural and human systems. The natural system encompasses availability and quality of water while the human system constitutes utilization of water resources, waste production, and pollution of the resources. Thus, IWRM concomitantly addresses the integration of natural and human systems, which in turn include the integration of various sub-systems as represented in Figure 1. In a pragmatic sense, IWRM negotiates among various actors, sectors, and their interests. It coordinates resources -land and water, as well as among stakeholders who share these resources.

\section{Materials and Methods}

The study generated data for this paper from household and institutional surveys, in-depth interviews with key informants, focused group discussions (FGDs), direct observations and workshop participants, and secondary sources. First, the paper drew on the perspectives of water experts $(n=15)$ as a benchmark to understand and assess the existing situations, the institutional performance in the Awash Basin to create holistic and integrated resources management among various entities. This helps to comprehend and shed light on the enabling institutional environments in the basin. Second, a case study of Fentale district from Awash River basin was employed to generate evidences on situations of various aspects of water resources management and its implications on household water security at micro level. We selected the district because of severe water crises triggered frequent drought and environmental resource degradation. As a result, it is experiencing an increase in competition for water among various users. This has affected household level resilience capacity and weakening of the local institutions and customary practices to cope with shocks and deal with water management. The data was collected from 400 randomly selected households.

Third, face-to-face in-depth interviews were conducted with 38 institutional representatives [academia, Donor, NGOs, CSOs, businesspersons, and local communities]. In addition, 16 FGDs were held with various members of local community [WUAs, water committee members, elderly and women]. In order to manage both in-depth interviews and FDGs, checklists were developed with full protocol. The ethical standards were maintained; consents were obtained to record and transcribe the 
information using mobile phone, the interviews and discussions were coded; respondents name were also kept anonymously.

Forth, direct observations of industries, sugarcane estate and factors, plantations, irrigation infrastructures, water supply schemes, and dams were made. These have provided a first-hand understanding of the problems of water and its integration to other sectors. In addition, various workshops and stakeholders' meeting on water issues were supplemented to triangulate and validate some evidences. The workshops attended are summarized in Table 1. Finally, secondary sources and literature, which include various institutions' agendas, reports, memoranda, minutes, and other documents (project documents, workshop proceedings, journal articles, policy, planning, and strategy documents) and archives (water-related legislation, laws) was consulted and crosschecked and triangulated with other sources.

Table 1. Workshop attend, theme, and date

\begin{tabular}{llll}
\hline \multicolumn{1}{c}{ Date } & \multicolumn{1}{c}{ Workshop title } & Participants & \multicolumn{1}{c}{ Place } \\
\hline Jan.12-13, 2017 & $\begin{array}{l}\text { Addis Ababa-Adama Water Resource } \\
\text { Management and Protection } \\
\text { Framework (AAWRMPF) }\end{array}$ & 33 & Addis Ababa \\
Jan.17, 2017 & AAWSA water quality monitoring & 10 & ST\&B, Addis Ababa \\
Jan.18, 2017 & Water resources information & 25 & Addis Ababa \\
March 28, 2017 & $\begin{array}{l}\text { Awash River Basin strategic planning } \\
\text { sensitization } \\
\text { (AAWRMPF)expert validation }\end{array}$ & $>200$ & Addis Ababa \\
May 13, 2017 & & 17 & Addis Ababa \\
\hline
\end{tabular}

Source: own data

The data collection emphasized:- how water sectors are working with other sectors, the interaction and relationship between upstream and downstream users, the existing water quantity as well as water quality, various water uses such as irrigation, livestock, domestic, and other livelihood uses, sources of water for particular purpose and their tradeoffs [ surface and ground waters], the complementariness and competitions among various uses, pertinent actors and their roles in water management such as industries, hydropower plants/dams such as Koka, small/large scale farms including state and private firms, etc. The data were collected between October 2015 and May 2017 at various levels, involving multi-scale analyses. The data collected from households and actors was entered into SPSS Ver.22 and descriptively analyzed. The data from various informants and discussants, and other secondary sources were entered into Excel Spreadsheet, thematically summarized, and content analyses were employed [28]. Vensim Version 7.2 [29] used to analyze the data. It helps to analyze the dimension of the relationship among entities in the various systems and subsystems. Multiple sources of data were triangulated to verify, validate, and seek for convergence of some sensitive and contentious information that need cross-referencing and data triangulation[30, 31].The results are presented in various visual techniques and narration of qualitative information.

\section{Towards IWRM: an Over-Romanticizing Myth or Implementable Reality?}

Since its existence, the Ethiopian Water Resources Management Policy did not achieve sufficient institutional performance against its core principles $[15,23]$. It only realized three River Basin Organizations; namely Awash Basin Authority in 2008, Abbay River Basin in 2008, and Rift Valley Lakes Basin Authority in 2011. The latter two are not functioning. The Awash Basin Authority too could not put into practice the policy statements into practice hence the principles of IWRM. In the policy document, the IWRM tenets have meritoriously ordered many of the recent trendy, fashionable, and politically correct but operationally fuzzy parlances (see Table 1). 
Table 2. Principles of Ethiopian Water Resources Management Policy relation to IWRM

Ethiopia has adopted IWRM in 1999 as a general framework for water resources management. The fundamental principles are aimed to guide equitable, sustainable and efficient development, utilization, conservation, and protection of water resources in Ethiopia. The principles include:

1) Water is a natural endowment commonly owned by all the peoples of Ethiopia.

2) As far as conditions permit, every Ethiopian citizen shall have access to sufficient water of acceptable quality, to satisfy basic human needs.

3) In order to significantly contribute to development, water shall be recognized as both an economic and a social good.

4) Water resources development shall be underpinned by rural-centered, decentralized management, participatory approach, as well as an integrated framework.

5) Management of water resources shall ensure social equity, economic efficiently, systems reliability and sustainability norms.

6) Promotion of the participation of all stakeholders, user communities; particularly women's participation in the relevant aspects of water resources management.

Source: [25]

Yet, the policy has gained tremendous applauses from donor agencies as it was fashioned with the parlances of IWRM. It was, thus, called 'comprehensive' and 'all inclusive' even without fashioning 'water security'. The policy was successful in assaulting the eye and thought of the donors and NGOs. Consequently, it secured incredible funding following philanthropic logic as [32] call it, including from the World Bank and UN agencies. It seems that the concept included in the policy for the sake of attracting funds, or to obtain greater national and international acceptance and visibility, and enticed the eyes of the various donors. In reality, the statements in the policy are tremendously a rhetoric and the implementation has been so far meager.

The policy was turned into strategic and programmatic focuses. The strategy did not show the roadmap of IWRM: what, where, and how to integrate. The water sector development rather was taken by the wave of MDGs, with donors putting funds to it. It mainly focused on WaSH without proper coordination among pertinent actors until 2013 when WaSH Implementation Framework (WIF) came into existence ${ }^{5}$. WaSH was a vehicle navigated all aspects of water discourses in the country. As a result, Ethiopia has achieved MDGs target- cut by half the proportion of people without access to water supply and sanitation- two years before actual plan set [33]. Even though MDGs has increased water supply coverage from merely 17\% in 1990s- the lowest of Sub-Saharan African- to $65 \%$ in 2015 , the destination to reach water security is remaining slothful due to a temporal and spatial variability of rainfall and institutional barriers. Improving WaSH access coverage is not an end for water security because the state of water access, availability, and safety is so fragile that sustainability issues always surfaced.

Despite, huge investments in infrastructure and increase WaSH coverage in the last 18 years, little successes have been documented regarding IWRM at the basin scale. Integrated Water Resources Management (IWRM); system thinking; water security; Awash basin; Ethiopia. Over the period, two trends were observed. Donors and NGOs as a part of international commitments such as achieving MDGs dominated the first scenery. The second was ambitious state projects, which targeted the big dams for hydropower and large-scale commercial farms. These big dams require huge money. Ironically, it is 'putting all eggs you have in a basket'. These projects have been also criticized for social and environmental externalities [34]. The impact is particularly execrably high when compensation for the displaced people from their livelihoods and land resources are barely paid.

\footnotetext{
${ }^{5}$ WIF was signed among Ministry of Water and Energy, Ministry of Health, Ministry of Education, and Ministry of Finance and Economic Development, in 2011. The purpose of the framework was to create coordination, harmonization of Water Supply and Sanitation (WaSH) stakeholders, consolidated budgeting for one WaSH program. It aimed to achieve 98.5\% water supply and 84\% improved sanitation access coverage by 2015.
} 
In the Awash River Basin, majority (68.64\%) of the irrigation schemes is dominated by community irrigations (See Figure 2) controlled by Water User Associations (WUAs).The irrigation systems are governed by the WUAs. The WUAs do not pay for water construction, use, and management but the members contribute for O\&M of the schemes. Governed by their own bylaws, sometimes, WUAs collect fines from members. Yet, the fees collected from members are inadequate to manage water resources on sustainable base. In addition, there are state farms, private, and smallscale farmers. They have all complain the scarcity of water in the basin not because of the dearth of resources but scarcity emerging from poor management and conservation. This calls for holistic approach to manage land, water, various uses, and users.

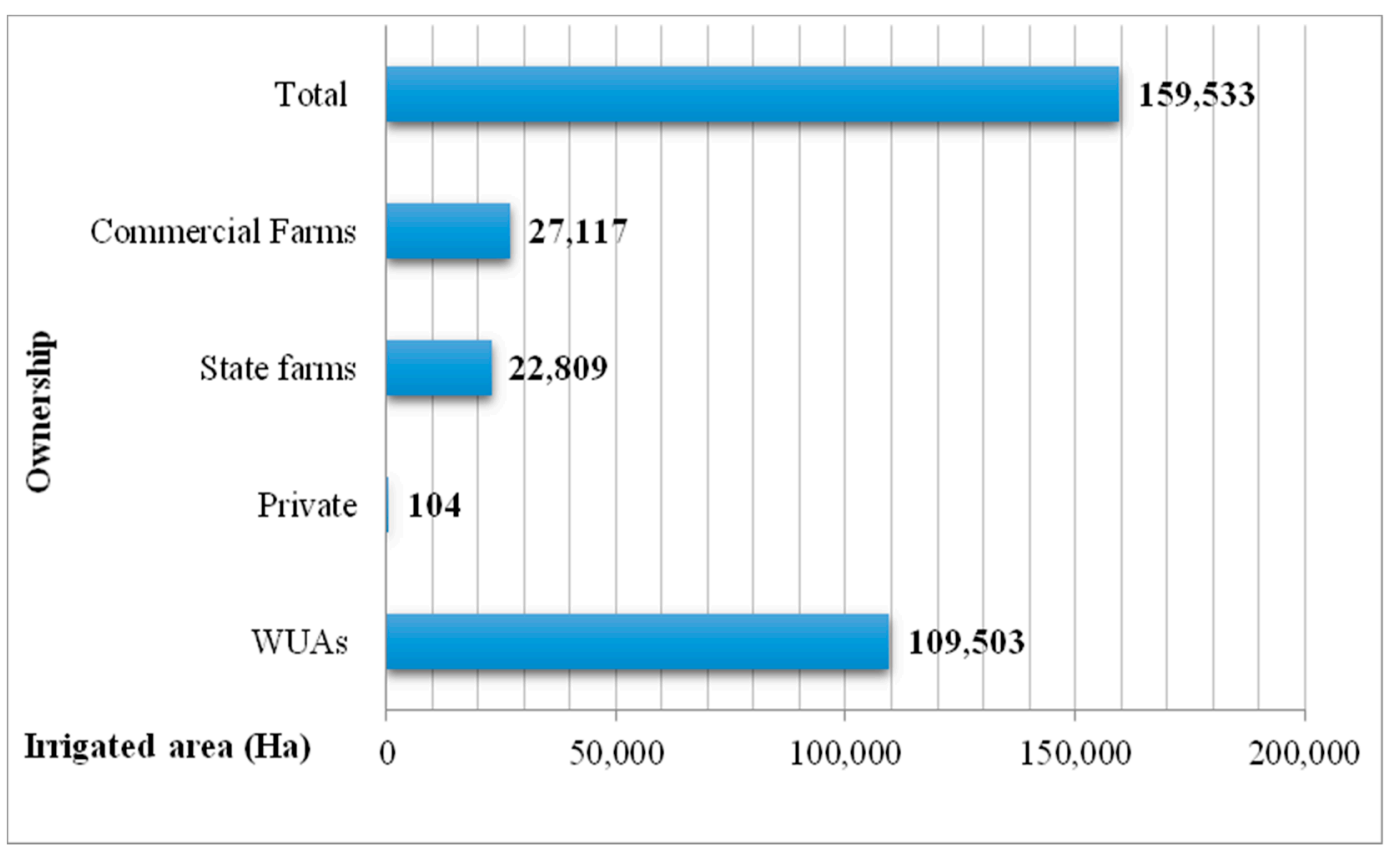

Figure 2. Irrigated area and types of ownership in the Awash Basin Source (Bases on [35]

Admittedly, the AwRBA is striving to coordinate various users because it is a key mission of the Authority. It has a broad vision to see the basin as a model river basin in Ethiopia, in which comprehensive and IWRM system established. The Authority is swinging with values such as innovative and creative, participatory, equity and accountability, quality first, availability, environmental sustainability and development, continuous learning, teamwork, and detesting corruption in the River Basin Organizations (RBOs) context. The values seem to promote IWRM. Nonetheless, beyond tattoos on the office wall, these values are neither implemented nor internalized into day-to-day activities of the office. IWRM principles are not envisioned systemically and uniformly in various hierarchy and sectors. For example, while Awash Basin Authority, BHC, and MoWIE have the vision to achieve IWRM, Regional Water Resource Bureaus (Afar, Oromia) have suspicious on its practicality. The latter believe that they have no problem to work in integration but the RBOs compromise the powers and duties enshrined in the regional state to plan and execute water resources. Interviews with regional and district levels stakeholders eloquently illustrated that the motive to put water resources management under RBOs, without the consensus of the pertinent stakeholders is to gain control over water resources. Under such power dynamics, the regions and districts are confined to implement small-scale infrastructures such as irrigation and artisan while Federal agencies gain control over larger projects. They justified that the current institutional arrangement is not fair as regions have also a motive to use water for socioeconomic development of the local people.

The donors and NGOs are promoting and funding the implementation of IWRM principles as a useful and promising tool to achieve water security in nutshell. The Civil Society Organizations (CSOs) and other external stakeholders also promote IWRM. They believe that the implementation of IWRM should be through a bottom-up and decentralized approaches. Until now, the push to 
IWRM is mainly top-down that rarely consulting the regional, district, local, and other collaborative stakeholders. In addition, IWRM is affected by uncoordinated interventions as illustrated by an expert at District Water Office in Amibera. He reported that

water sector is very delicate here because of water scarcity. Yet, water planning, management, and decision-making processes are increasingly messy. The training we received on integrated principles yet giving a sermon of policy statements are merely valid here. Various stakeholders 'hit and run' and end-up with false promises. Sometimes, we meet once a year; we talk about principles and go. They scared to go to action- integration. Thus, everything is a talk that we are far from rational and efficient water resources management despite the growing challenges.

The interests and priorities of these stakeholders could not be addressed visibly in the process that they are hesitant to the outcome of IWRM. For example, a group interview ( 4 men and 3 women) with Dire reservoirs area, major water suppliers of Addis Ababa City, agitatedly revealed the context and questioned how IWRM is promoted in their areas as follow:

some NGOs, Federal governments, and Addis Ababa City Administration dictate us to manage watershed surrounding the reservoir. We make our livelihoods from farming, grazing, quarrying, etc. near to the reservoirs. We cannot stop these because these are the sources of our livelihood. We need alternative sources of livelihoods to stop farming or quarrying so that protect the dam. As you can see we do not have water supply services despite the dam is here and the pipes pass through our home yard to serve the City. We are underprivileged of the dam. Thus, what people talk about integration is non-sense for us. We never directly benefit from it.

In the Awash basin, the presences of Dutch organizations through various Water Board Authorities, Meta-Meta, International Water and Sanitation Centre (IRC), Vitens Evidas International, Dutch Wash Alliances, etc. are strong. They have been framing institutional arrangements that promote IWRM in the basin through customizing the Dutch model of water resources management. Paradoxically, the interventions to support IWRM have mainly on project base that disconnection could be possible when external funds are ceased before internal capacity is developed. Moreover, the interventions often failed to address the underlying systemic reason that justifies why IWRM is not properly implemented. The policy and subsequent proclamations and regulations did not thoroughly address the socio-political system complexity of water resources when both Federalism and RBOs co-exist. The policy faced the difficulty of harmonizing bothpolitical and hydrological boundaries. Interviews with some higher officials revealed that IWRM would be difficult under the present institutional structure. Hitherto, the fragmentation of efforts exacerbated water insecurity in the basin. For example, most schemes failed to design for multipurpose uses that deepening the water stress (Figure 3). It is, thus, in this sense that pragmatic IWRM from the perspective of system approach is needed to understand water resources. 


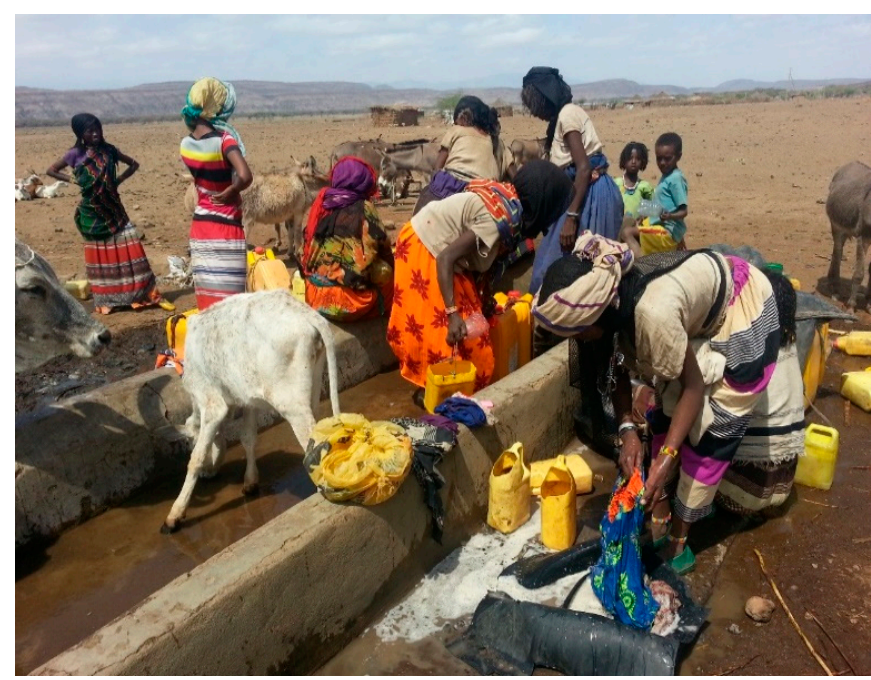

(a)

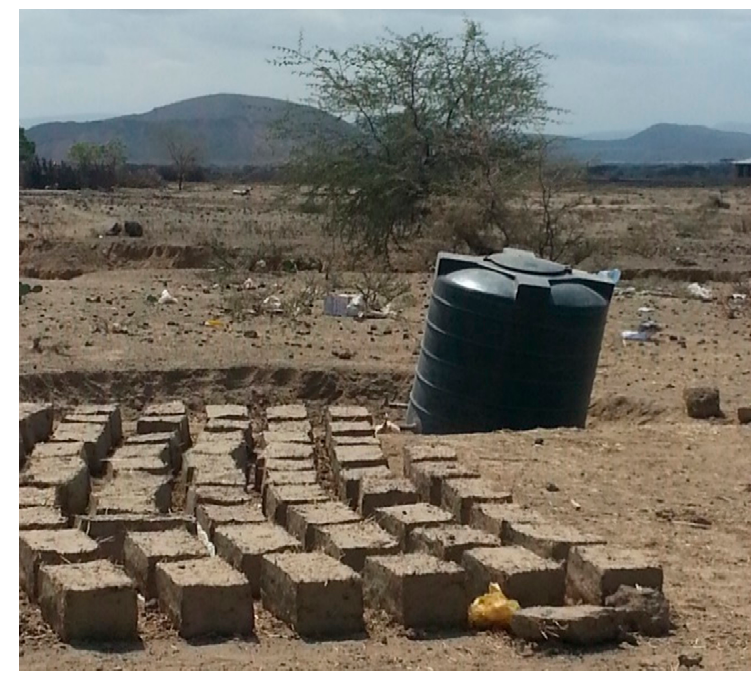

(b)

Figure 3. Both pictures are taken from Harokersa village of Fentale district in the Awash Basin. (a) Illustrates the issue of infrastructure design and water scarcity as the driving force to water insecurity. Livestock and human uses are from a single source. People wash clothes, haul water for domestic uses from the same point into jar cane. Yet, the surrounding water point is unclean. (b) Shows water for brick makings that water is used for multiple uses. Photo credit: Fieldwork

A case study of Fentale district from the Awash Basin also concurs with the paucity for IWRM to meet various needs and interest. It further showed that only $2 \%$ of the households have access to piped water from private and public taps for domestic purpose. $39.6 \%$ and $28 \%$ of community in this district rely on irrigation canal diverted from rivers and streams/lakes, respectively to obtain domestic water uses (see Figure 4). The tradeoffs and synergies of various sources of water and multiple uses are unclear and intricate that can only be visualized from a system perspective.

Piped water from

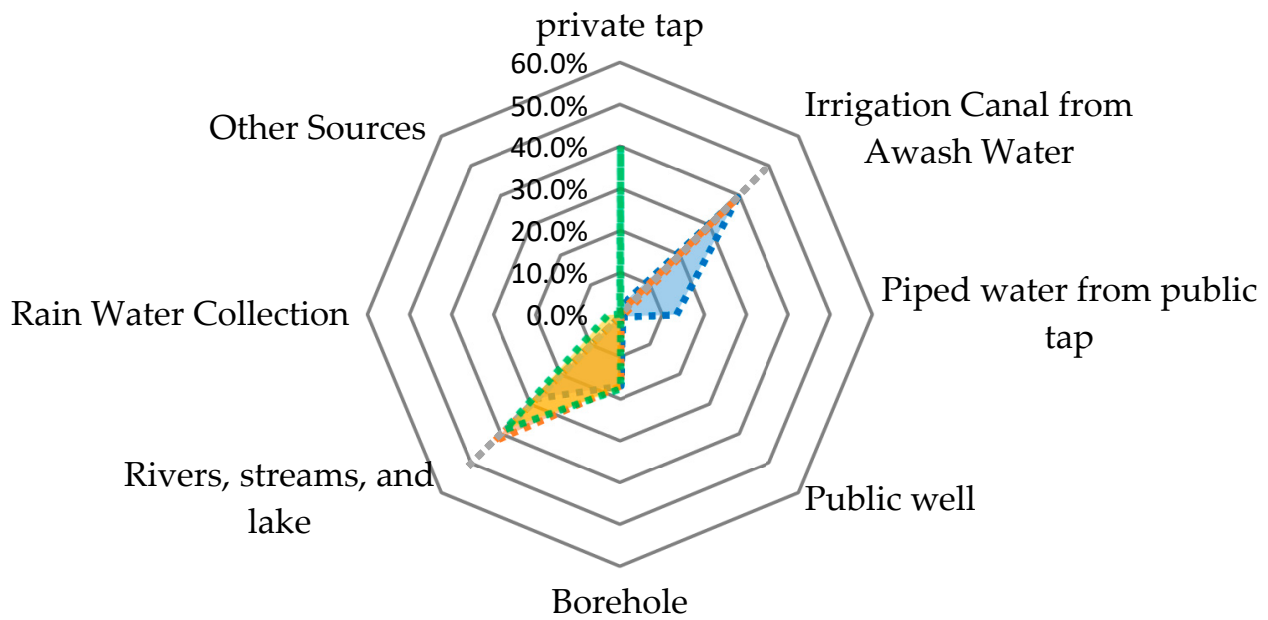

\section{:DOMESTIC SOURCE LIVESTOCK AGRICULTURAL OTHER PURPOSE}

Figure 4. Source of water for different purposes in the Fentale district of Awash Basin (Fieldwork).

Generally, the study observed that setting policy statement alone could not guarantee the implementation of IWRM. It can be argued that one of the mechanisms to overcome such discrepancies is to approach water resources management as a system that brings wider stakeholders at multiple scales on board. In other words, implementation of IWRM relies on discussions and consultations of different actors, and consideration of multiple uses and sectors. The approaches so 
far followed have overlooked these aspects. The undeniable fact is that there are various efforts to instigate IWRM. However, they have neither instituted at the basin level nor provided any real guidance to the water professionals and practitioners as to how the concept can be operationalized. It seems that the concept was included in the policy for the sake of attracting funds, to obtain greater national and international acceptance and visibility, or entice the eye of the various donors. The policy even biased to domestic water supply under the guise of MDGs. In doing so, the approach so far followed overlooked the balance among multi-purpose uses, sectors, and actors that water scarcity and stress have growing in the populous basin like Awash. At the national level, therefore, there is a need to reconcile the federal institutions, Awash Basin Authority, and regional bureaus to promote pragmatic IWRM.

\section{Systems Approach to Water Resources in the Basin}

The basin system can be categorized as natural and human systems [27]. Each is a part of larger basin system functioning as independent system but interacting one another. The natural system involves various biophysical elements that affect water security. It includes the groundwater, the land and water resources, upstream and downstream, and water quality and quantity sub-systems. The human system constitutes various socioeconomic realms such as various stakeholders, water use purposes, sectors, and interests, which have their own subsystems within the human system. It is fundamentally necessary that the two systems operate holistically and synergistically for functioning of the whole basin system. The proper functioning of the systems, of course pragmatically, enhance IWRM and hence water security.

\subsection{The Natural System}

Within the groundwater subsystem-aquifers, there is lacuna of rules or laws regulating and governing the subsystem. Standards and governing laws for abstraction, drilling, and use of groundwater in the basin are not clearly defined that the subsystem is dominated by a temptation of free-riders ${ }^{6}$. Any user can drill water either using rig machine or hand-dug for any purpose if they can afford the cost of extraction. The groundwater engaged a range of water users from deep drilling for irrigated agriculture to shallow well for domestic purposes. Interviews with experts attested that there are no collective actions on groundwater management (allocations, utilization). The action of one actor is unknown for the other actors. Neither fees nor tariffs are set for and collected from users. Some are licensed others are arbitrary. For example, several medium and small-scale agricultural land operators, as well as industries-the massive water users-are not licensed and provided with water use permit. This implicates the extent to which the key stakeholders completely overlooked groundwater governance in the basin. It is a conspicuous manifestation of institutional failure in the Awash Basin. Thus, the exploitation of groundwater subsystems are uncoordinated and become a 'tragedy of the common', which needs groundwater governance and proper institutional framework.

The study also revealed that surface water resources subsystem is poorly managed and allocated, in which collective actions are not operational. Surface water subsystem in the basin comprises all rivers, lakes, ponds, dams, and other storage due to runoffs and/or groundwater recharges. First, it is the major source of commercial farmers to irrigate farms through pumping out the running river. About $97.3 \%$ of irrigated areas are furrow/surface irrigation systems. This irrigation system is inherently inefficient in terms of water use. FAO [35] estimated that the efficiency of furrow irrigation in the basin is about $30-40 \%$ compared to $80-90 \%$ of sprinkler and $90-95 \%$ of drip systems. Yet, a few commercial farms have introduced drip (1.9\%) and sprinkler $(0.8 \%)$ irrigations. The farms engaged in high-value crops including floriculture, Wonji Sugarcane plantations, fruits, and vegetable production. Drip and sprinkler irrigation types can substantially save water. Second,

\footnotetext{
${ }^{6}$ A free-rider is somebody's behavior who exploits the common pool resources such as water without taking into account its sustainability. The free-riders uses resources at the cost of the others. When the free-riders prevail, the other users are also triggered to increase the exploitations of the resources because it seems better to take the last bit of a resources before it is finished, rather than to have nothing at all [36] (p.39).
} 
appropriate water pricing is not only essential but also a prerequisite for efficient water use through triggering market mechanism [37]. Ingram et al. [38](p.332) also noted that 'water pricing can be expected to facilitate entry into the market by new users, at least in the short term, and to lead to greater efficiency in use'. The water pricing mechanism can integrate water as a natural resource with a significant economic value that ensures social equity. It promotes efficient use to avoid scarcity and pollution that centered on the affordability of the fee to overcome inaccessibility. Furthermore, proper water pricing mitigates abuses through taking into account contextual tariff setting. Although the Ethiopian Water Management Policy has put the economics of water cost and pricing, which valued water as economic resources as much as it emphasized as social values, the pricing system in the basin is working against the principle of IWRM. It is not treating water as an economic good.

Still, there is limited water saving methods and practices in the Basin due to poor pricing mechanisms. Some irrigated farms are not paying water charges at all and a few are paying a nominal price of 0.13 US\$/M3. Large-scale farms can easily access water at a cheaper cost that there is no adequate incentive to push them to invest on water-saving irrigation technologies such as sprinkler or drip irrigation. While the cost recovery fees have been well established for urban water supply since 1999 with respect to drinking water, little progress has been made for rural water supply (drinking and livestock uses) and irrigation water. Rural drinking water is based on the principle of covering operation and maintenance (O\&M). Until now, there is no clear pricing policy for largescale irrigation schemes, industries, fishery, water bottling, pollution control, hydropower, and recreational uses of water in the basin (See Table 3). The Awash Basin Authority attempted to collect some tariffs for flood protection though it is negligible with the increasing flood frequency and coverage. Moreover, there is an intention that the active involvement of government is to support those who could not pay for water resources development given the poor community could not pay for O\&M, encourage full cost recovery in the urban area, and promote cross-subsidization. The policy speculated that all pricing schemes should take into account the willingness-to-pay by users as a tool to encourage water resources sustainability.

Table 3. Water pricing system in the Awash River Basin (X=Not accounted, $\checkmark=$ Accounted)

\begin{tabular}{llllll}
\hline Pricing system & Irrigation & $\begin{array}{l}\text { Domestic use } \\
\text { Urban }\end{array}$ & $\begin{array}{l}\text { Domestic use } \\
\text { Rural }\end{array}$ & $\begin{array}{l}\text { Industrial } \\
\text { Use }\end{array}$ & $\begin{array}{l}\text { Other } \\
\text { uses }\end{array}$ \\
\hline Full cost recovery & X & $\checkmark$ & X & $\checkmark$ & X \\
Partial recovery & $\checkmark$ & X & $\checkmark$ & $X$ & X \\
Full subsidy & X & X & X & $X$ & X \\
Operation \& & X & $\checkmark$ & $\checkmark$ & $X$ & $X$ \\
Maintenance & & & & & $\checkmark$ \\
No clear pricing policy & $\checkmark$ & $X$ & $\checkmark$ & $X$ & $\checkmark$ \\
\hline
\end{tabular}

Source: Survey of Actors $(\mathrm{n}=15)$

Nevertheless, we found out that most users are not paying in accordance with the value of water. While the smallholder farmers (both modern and traditional irrigation), artifacts, mining, brickmaking, and other productive purposes can use water free of charge, the pricing mechanisms for commercial and industrial purposes are vague and inconsistent. Some large-scale private farms and state sugarcane plantations freely divert or pump out water directly from the river. Industries also dug their own medium and deep well still do not pay water extraction fees. Of course there are not licensed. The permitting and licensing of the surface water for the various purpose were also not uniform. In urban water supply sector, surface water is so poorly managed that some waters are stolen, illegally connected, or wasted. One of such indication is the high Non-Revenue Water (NRW) in major cities. For example, in Addis Ababa City where there is a growing water scarcity, NRW is estimated at $36.5 \%$ [39]. This affects domestic water security of other residents of the city and a community where the water is originally extracted.

As the value of water is undervalued, the existing water resources could be mismanaged and abused. This gradually induces pollutions and scarcity. Water price for irrigation, domestic for urban, domestic for rural, and industrial uses are rarely revised to reflect the changing cost of water 
management and scarcity value of water. The setting of water pricing is not set arbitrary. It is procedural. First, the Ministry of Water, Irrigation and Energy (MoWRIE) and/or Regional Water Bureau prepare the price proposal. Then, the Ministry presents it to the council of people's representative -regulatory body and the respective water utilities and departments implement fee collection at users' level. The water pricing policy in the basin needs to be reconsidered so that the value of water would be released at policymaking level. However, pricing water for irrigation and industrial water uses are not clear.

In addition, the effectiveness of water policy in promoting technologies, extension, and wastewater recycling are non-existing. The installations of water measuring devices are insufficient. The already installed once are not functional. At present, there is no technology to estimate water use of the major users in the basin. Interviews with stakeholders in the basin confirmed that most water users such as industries/ farms, households, and urban wastes are directly releasing solid and liquid wastes, as well as effluents to the water bodies in the basin without treatment or any attempt for recycling. The irrigated farms are expanding in leaps and bounds but not hand-in-hand with the advancement of technology to save water, to monitor water uses, and to minimize pollution of surface and groundwater systems. The rush to expand irrigated farming practices at Metahara, Abadir, Tendaho, Amibera, and central highlands would lead to perils without proper collective actions. The expansion of the hypersaline lake Beseka that intruding into the river (diverted to the main Awash River below Methehara Sugar Estate) from the previously closed lake has also been a major concern and compromising the water quality in the lower basin. The extreme hydrological phenomenon such as floods and droughts, which evicted several people, are not properly managed. The major reason is that pertinent institutions and actors are not collaboratively working together towards an IWRM.

The general picture in the basin showed that water-pricing policy is haphazard and not systemic [40]. The uncoordinated water pricing system has discouraged technical innovation for water resources management in addition to aggravating 'tragedy of the common'. For obvious reasons, when water resources are not properly managed and undervalued, water security suffers. This gradually induces pollution and scarcity of both the surface water and groundwater subsystems as the relationship and integration of the two subsystems received little attention. For example, informants agreed that low irrigation technology coupled with inconsistent regulatory mechanisms for water abstractions, pollutions have affected the integration and management of surface water groundwater. Furthermore, it affected the quality of water available to people for various purposes.

In other words, the ground and surface water sub-systems as elements of natural system need integration. The natural system also depends on how the land and water resources managements are properly and coherently integrated. Land degradation is the major problem in the Awash Basin [41] due to deforestation, urbanization, and intensive cultivation. As such flooding during excessive rain and drought during water scarcity often hit the entire basin system. Such phenomenon is key causes for water quality deterioration and diminishing water quantity. In addition, the upstreamdownstream dilemma has hardly notice in the Awash basin system but it is a critical to comprehend the state of water security. The downstream users believe that the actions of upstream water users have affected negatively the the quantity and quality of water available to them. Industries are releasing effluents; agriculturalists use agro-chemicals recklessly; cities dispose all sorts of wastes directly to water bodies; and land and water resources management and conservations are inadequate that the downstream actors are suffering from pollutions, water scarcity, and floods.

\subsection{The Human System}

Within the human system, complex realities are prevailing and emerging. This is because diverse behaviors of the actors, various interests, and uses are central to the basin management [40]. This system is also so dynamic that it poses complexity and non-linearity in interaction [6]. For example, the interest of pastoralists in the basin system conflicts with irrigators who engaged in agriculture and delineate their space. This mainly not only due to fierce competition over water access but also as a result of land resources within the enclave of the key grazing areas, which the pastoralists utilize 
rotationally between dry and wet seasons. Likewise, the agriculturalists see pastoralists as 'antidevelopment' on the wrong perception that pastoralism is not feasible and not contribute to agricultural development that their priority must come first. The other interaction in the basin is a grave competition between the large scale and small-scale irrigators over access to both land and water. Most small-scale irrigator are early settlers while large-scale famers are latecomers in the form of 'investors'. Some of these large-scale farms are owned by state. Recently, some of them are privatized. The Kereyyu and Afar pastoralists have started irrigated agriculture. As a result, during the dry season- December and May, there is always water scarcity. Scarcity often escalates conflicts to the extent of water looting and violence. Sometimes, irrigation canals damaged. That it affects the livestock and drinking water access. The private sectors including the industrialists and service providers are complaining of water scarcity. They stressed that public sectors responsible for water construction, management, and allocation are irresponsive and unaccountable to rampant water crises.

Research, extension, and education are essential entities to generate knowledge, disseminate, and raise awareness about IWRM. Research and training institutions are carrying out researches and document practices and challenges. So far, some water saving technologies such as drip and sprinkler irrigations, and reservoirs remain within the vicinity of the large-scale farms and state plantations. These facilities are not economically affordable and replicable to small-scale agriculturalists. We came across that research and training institutions in water sectors are often relying on donors and state funding to carryout research and trainings including the AwRBA. The AwRBA are principal body assigned to undertake research and development regarding the basin. Given the staff and financial capacity, the Authority did not implement any groundbreaking research, development or technology generation. Interviews with experts and stakeholders demand water use related awareness creation, training, and extension advisory services. However, there are sporadic studies by academician and Regional States for specific purposes. Thus, the AwRBA did not link itself with the regional and local governments, communities and stakeholders including academic institutions.

Despite the public sectors have recognized the problem of water resources crises in the basin, there are limited investments on technological solutions to manage and conserve the resources in integrated manner. For example, the management of solid and liquid waste is insignificant. The campaign based watershed management is also unorganized and did not engage relevant stakeholders. It was merely perceived as the onus of smallholder farmers on a plot basis. Post watershed development was rarely monitored. Perhaps, the efforts so far made by donors, NGOs, and CSOs to support water access for domestic, livestock, and small-scale irrigation, and other productive uses should be the central part of the human system, which need to be seen pragmatically.

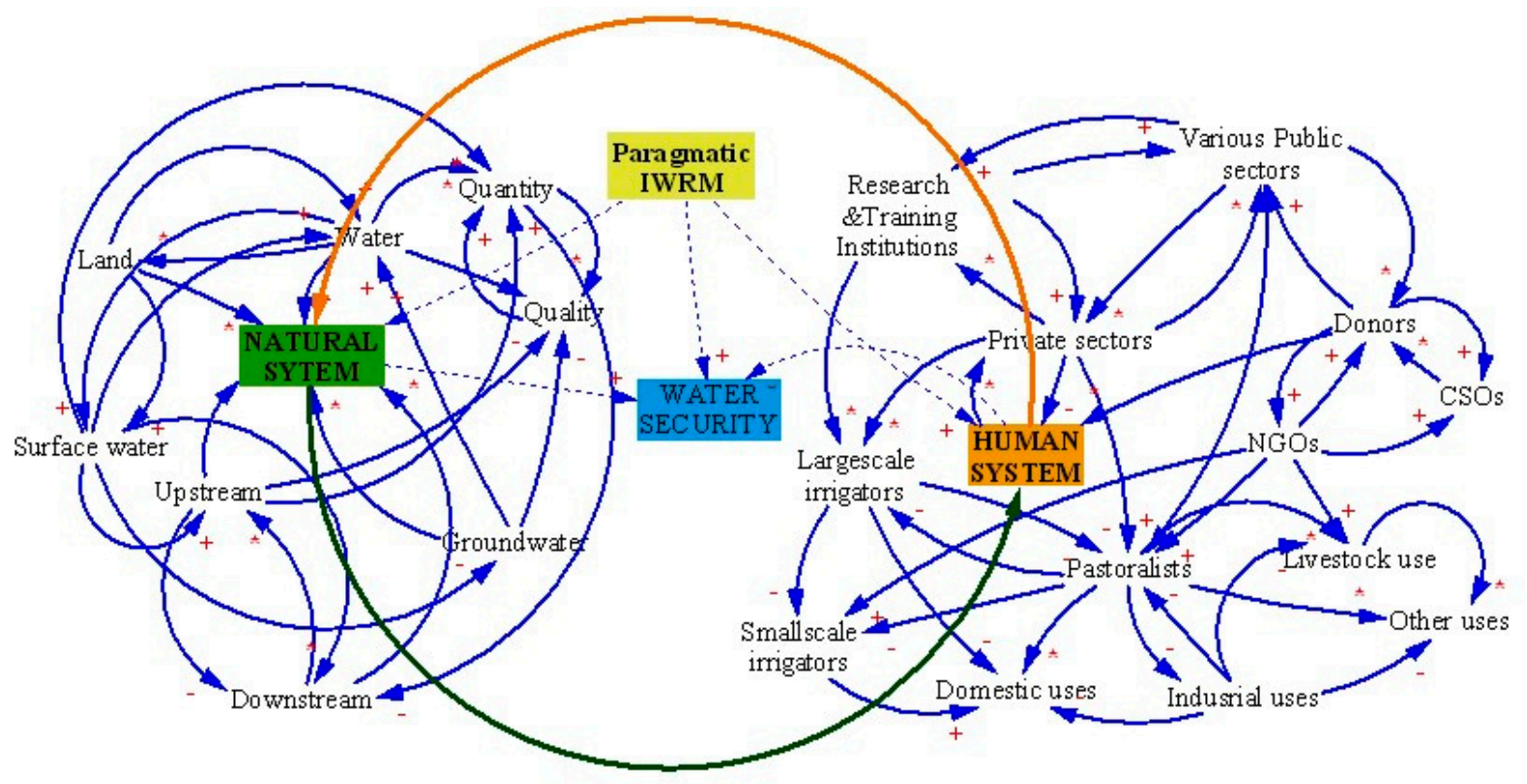


Figure 5. System approach of water resources management in the Awash River Basin. The (+ ) sign donates positive relationship among elements in the particular system. The (- ) sign represents negative relationship. The $\left(^{*}\right)$ shows possibility of both relationships. The broken line indicates the interaction of various system to water security while the bigger loop connecting natural system to human system (green and orange show the loop that back and fore system linkage that can occur holistically, respectively). Based on field data

As shown in the Figure 5. The interactions of various subsystems among each other and within the particular human and natural systems have complex causal relationships. While some elements in the particular system affect the other negatively, some have negative relationships. Some have no relationships. Still, neural links prevail due to poor collective actions, poor system integration and management. These suggest failure of integration between various systems. Therefore, integration requires a systemic means to bring the links among the entities as pragmatic as possible so that the entities contribute to the natural and human systems and thereby the whole basin system. The realization of functional basin system driven by IWRM entails enabling institutional environments in addition to understanding the nature and synergy of the two major systems.

\section{Search for Enabling Institutional Environment for IWRM}

The institutional environments in the basin are always in motion with the changing political, economic, and social circumstances. In many cases, water institutions have evolved over long period because institutions pass through interactive processes [42]. They potentially tie together to numerous agencies, actors, and sectors, who often occupied with various responsibilities. Their exclusion affects water management that they are often necessary for them to coordinate plans, negotiate differences, exchange technical information, and generally cooperate in the achievement of concerted policy and administration [38]. Institutions are enabling environments under every circumstances. Sometimes, new institutions disrupt the existing settings and cause inefficiencies in water resource allocations, and distribution of costs and benefits among resource users. For example, Saleth \& Dinar [43]) argued that institutional change has a mixed pack. While some induces efficiency, others constrained it. Thus, institutions can be explained in terms of 'capacity to produce' either collective benefits for all groups of actors and distributional advantage for powerful stakeholders. There is 'no silver bullet' solution for functioning of IWRM in the basin but contextual rationally is useful. Instead, the design of institutional environments that enable the human and natural systems, can regulate the actions (and non-actions) of the different stakeholders [44], are needed.

Experts also advice that in order to make water users and vibrant stakeholders for water resources a management as well as the government bodies and AwRBA as key players of the game, incentives are necessary. The Water users need to be frequently consulted, oriented, trained, and introduced to new water use and saving technologies as an incentive package. The AwRBA and pertinent government bodies should create a harmony to plan and implement IWRM and to enforce the already existing laws on water use, permit, pollution control, and conservation. Thus, as mechanism of check and balance, enforcement of laws alone is not sufficient but it must be accompanied by proper incentive.

We identified, two broad sources of institutional environments need to be considered as enabling in the Awash River basin. The first are sketched to enabling political ideologies and technological advancement to allocate water resources more efficiently. The second sources of institutional environment emanated from external supports- multilateral and bilateral donor agencies- in terms of economic and political agreements such as political liberalization, decentralization, or democratization of institutions. Both changes are influenced by the neoliberal thinking promoted by major donors such as the World Bank and the IMF of the early 1990s hijacked IWRM and affected water resources management in the development countries [16]. Curiously putting, enablers may turned to disablers when imposed from-above. In addition, uniform institutional environments may not work in water resources development. This is what Ostrom[45] 
calls 'institutional monocropping' which may be worsen and disturbs the basin system. A basin system is always dynamic because other systems or subsystems change within it. For example, under the circumstances of water insecurity, the way of thinking on water allocation and conflict resolution mechanisms could shift. The water users who often considered as beneficiaries under conventional perspective become 'customers' or 'clients' from system perspective as water availability moves from state of plenty to the state of insecurity [46]. This also calls for concurrent systematic shift in water institutions.

Under such change in systems, the rules and regulations of water resources development, use, and distribution often redefine which we call system dynamism. The dynamism of the system changes the existing supply and demand, as well as quality and quantity of water to reflect the reality on the ground. In contrast to the system perspective, stakeholders in the Awash River Basin perceive the government institutions as service providers whereas the service providers consider the water users not as clients but beneficiaries. Moreover, the water and related institutions adhered to sectorial thinking. The governing rules and regulations are obsolete that balancing demand and supply, as well as water quality and quantity were impossible. Thus, water is becoming scarce during the dry season and a surfeit during the rainy season.

The previous work of the same author identified that financial and human capacity are the major constraints of Awash River Basin in addition to vertical and horizontal coordination failures [40]. These pitfalls can be attributed to institutional capacity [47], which affect the enabling environment in which IWRM operates. The setting up of enabling environments should not be sudden, both physically and institutionally because it further upset the existing institutions. Thus, institutional environments must mitigate such instability, which potentially trigger political strains- for example, between the Regional States and Basin Authority, between the local community and large-scale water appropriators, as well as between the formal and customary institutions. Noteworthy, this paper is not proposing that change in institutional environments is always demanding because it may not necessarily yields positive outcomes. There are associated risks such as dismantling existing institutions exacerbate inequalities in water access, trigger environmental problems, and conflict of interests, among others. We rather argue that institutional change is desirable when it maximizes the goal of water security.

In order to analyze the percept of the enabling institutional environments for IWRM, about five criteria of water resources management and development institutions were weighed at Likert scale of five drawing on the indicators developed by[43,46]. The scores of the scale were converted to percentage. The first criteria is physical institutional environment in terms of ability to bridge overall demand-supply gap, physical health of water development projects; conflict-resolution efficiency (low cost and less time), smoothness of water transfers across sectors and regions, and smoothness of water transfers between users. The aggregate result gave $46 \%$ of possible capacity. The second is financial enabler that encompasses actual investment vs. investment requirements and cost recovery vs. expenditure, which scored $42 \%$. The third is economic aspect that rates the extent to which water prices cover supply cost and extent to which water prices cover scarcity value. In terms of meeting economic efficiency, it is perceived to be just $40 \%$ of what it ought to be. The forth is equity issues among regions, sectors, and different stakeholder groups, which remains lower than the average and maximum expected values. The final is progressiveness of water institution that takes into account factors such as effectiveness, flexibility, adaptability, technological applications, innovation, and openness to change, which scored the lowest of all criteria and $40 \%$ of maximum value.

The result showed that the performance indicators of all institutional enabling environments have rated below the expected average value (50\%) with the overall performance is still low $(42 \%)$, according to the perception of the respondents. Figure 7 is suggesting that the water institutions in the Awash River basin, as evaluated by the experts, are not to the expectation to ensure IWRM through safeguarding water availability, accessibility, and proper utilization on sustainable basis. There is need for further works to improve the enabling institutional environments to suit to IWRM. 


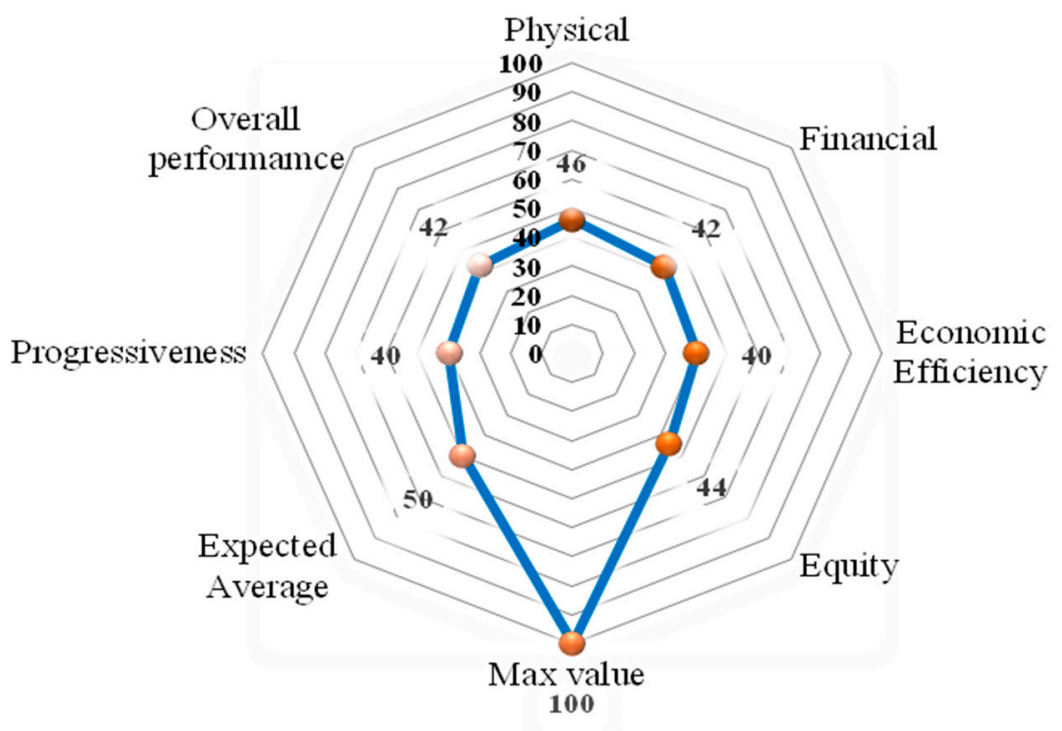

Figure 6. Performance of institutions in the Awash Basin (Actors survey 2016)

To subsume, the survey of literatures and institutional reports, as well as interview with experts revealed that in the last 19 years, little successes have been documented regarding IWRM at the basin scale in Ethiopia. This suggests that the rhetoric was not translated to practice and really. It entails that establishing River Basin Authority is not a guarantee for water security though the RBO is a prerequisite for management, coordination, and administration of water resources. We would like to close this section with argument made by Warner and colleagues. They implicated that what matters is the level of organizing and coordinating the stakeholders towards the same end -IWRM as systemic and pragmatic as possible. Narrated fully, Warner et al.[48](p.134) argued that

\begin{abstract}
Moving toward sustainable river basin management requires much more emphasis on developing, managing, and maintaining collaborative relationships for river basin governance, that build on existing organizations, customary practices, and administrative structures, rather than the current focus on the establishment of unitary river basin organizations. Where identity leads to collective action, it is more likely that culturally and environmentally sustainable practices will develop.
\end{abstract}

\title{
7. Conclusions and Further Implications
}

This paper draws on IWRM as systems thinking that recognizes the issue of water resources management holistically as it engages multi-actors and multiple sectors with diverse interests and priorities. Most previous approaches and existing formal institutions in the basin in cascading IWRM followed reductionism perspective that often centered the rhetoric of IWRM. The institutional arrangements will not enhance the water security at the basin levels without invigorating and revitalizing the 'old concept' of IWRM pragmatically. Pragmatically working with various stakeholders in a coordinated manner could avoid unnecessarily overlapping and fragmentation of efforts in watershed and basin managements. It also helps to bridge the discrepancies between policy and practices, as well as between rhetoric and realities that IWRM could move beyond a fashionable, buzzword, and trendy concept to making institutions work for water security at basin level.

IWRM in Ethiopia has failed to be realized not due to lack of policy and advocacy issues per se but the shortfall of the contextual practices. The failure to balance the natural and human systems and subsystems along with reengineering the enabling environments is key reason for setback of IWRM. Thus, operationalization of IWRM require functioning of the systems (natural, human), subsystems (e.g. surface and groundwater, land and water, etc.), as well as other elements within the subsystems.

Reasonably, IWRM needs to reconcile various aspects listed underneath: 
- Substantial strengthening of the information and evidence on the water uses, users, allocation, distributions, and water-related risks to reverse negative linkages, strengthen poor interaction, and strengthen positive interfaces;

- Ensuring that budget and finance mobilized from donors, the public, and water users through taking into account water as economic goods as much as public goods;

- Creation of awareness among stakeholders; encouraging the engagement of private sectors in water resources development and management; inculcate the culture of corporate social responsibility; establishing functional platform to cheer interactions and intricacies among the stakeholders; and

- IWRM need to be advocated pragmatically via enabling institutional environments in the basin context, and mainstream it to water and related sectors, actors, and users.

Acknowledgements: We would like to thank experts who provided information and documents used in this paper. We must credit them for their time and kindness under their busy schedules. We also express our heartfelt gratitude to the local communities. They were supportive and cooperative to share their opinions.

Author Contributions: The three authors designed the research. Reta Hailu collected, analyzed the data, and wrote the paper. Degefa Tolossa and Getnet Alemu contributed to write up and edited the paper.

Conflicts of Interest: The authors declare no conflict of interest.

\section{References}

1. Araral, E.; Xun, W. Comparing water resource management in China and India: policy design, institutional structure and governance. Water Policy 2016, 18, 1-13.

2. Moss, T.; Medd, W.; Guy, S.; Marvin, S. Organizing Water : The Hidden Role of Intermediary Work. Water Altern. 2009, 2, 16-33.

3. Long, N. Development Sociology: Actor perspective. $1^{\text {st }}$ Ed. Routledge and Taylor \& Francis: New York, USA, 2001; p.294.

4. Zeitoun, M.; Lankford, B.; Krueger, T.; Forsyth, T.; Carter, R.; Hoekstra, A. Y.; et al. Reductionist and Integrative Research Approaches to Complex Water Security Policy Challenges. Global Environmental Change 2016. 39, 143-54; doi: 10.1016/j.gloenvcha.2016.04.010.

5. Plummer, R.; de Loë, R.; Armitage, D. A Systematic Review of Water Vulnerability Assessment Tools. Water Resour.Man. 2012, 26, 4327-4346; doi: 10.1007/s11269-012-0147-5

6. Burns, D. Systemic Action Research: A strategy for whole system change. The Policy Press: Bristol. UK, 2007; p.194.

7. Simonovic, S.P. Managing Water Resources: Methods and Tools for a Systems Approach. VODOPRIVREDA 2008, 40,157-165.

8. Liddle, E.S. and Fenner, R. Water point failure in sub-Saharan Africa: the value of a systems thinking approach. Waterlines 2017, 36, 140-166; doi:10.3362/1756-3488.16-00022

9. Biswas, A.K. Integrated Water Resources Management: A Reassessment. Water Intern. 2009, 29, 248-256; doi: 10.1080/02508060408691775

10. Biswas, A.K. Integrated Water Resources Management: Is It Working? Water Resour.Dev. 2008, 24, 5-22; doi: 10.1080/07900620701871718.

11. Suhardiman, D.; Clement, F.; and Bharati, L. Integrated Water Resources Management in Nepal: Key Stakeholders Perceptions and Lessons Learned. Intern.J.Water Resour.Dev. 2015, 31, 284-300; doi: 10.1080/07900627.2015.1020999.

12. Kurian, M. Institutions for Integrated Management in River Basins: An Analytical Framework. IWRM: Colombo, Sri Lanka, 2004.

13. Grigg, N.S. Integrated Water Resources Management: Unified Process or Debate Forum? Intern.J.Water Resour.Dev. 2014, 30, 409-22; doi: 10.1080/07900627.2013.877338.

14. The Global Water Partnership (GWP) and the International Network of Basin Organizations (INBO). $A$ Handbook for Integrated Water Resources Management in Basins. Stockholm, Sweden and Paris, France, 2009; p.103; ISBN: 978-91-85321-72-8.

15. Adey M.; de Fraiture C.; Mehari. A. Integrated water resources management: contrasting principles, policy, and practice, Awash River basin, Ethiopia. Water Policy 2016, 18, 335-354; doi: 10.2166/wp.2015.049 
16. Petit, O.; Baron, C. Integrated Water Resources Management: From General Principles to Its Implementation by the State. The Case of Burkina Faso. Natural Resources Forum 2009, 33, 49-59.

17. Varis, O.; Enckell, K.; Keskinen, M. Integrated water resources management: horizontal and vertical explorations and the "water in all policies" approach. Intern.J.Water Resour.Dev. 2014, 30, 433-444; doi: 10.1080/07900627.2014.912130.

18. Araral, E.; Yu, D.J. Comparative water law, policies, and administration in Asia: Evidence from 17 countries. Water Resour.Res. 2013, 49, 5307-5316; doi: 10.1002/wrcr.20414, 2013

19. Van Koppen, B.; Schreiner, B. Moving beyond integrated water resource management: developmental water management in South Africa. Intern.J.Water.Resour.Dev. 2014, 30, 1-16; doi: 10.1080/07900627.2014.912111

20. Smith, M.; Jønch Clausen, T. Integrated Water Resource Management: A New Way Forward, A Discussion Paper of the World Water Council Task Force on IWRM. Marseille: France, 2012. Pp.1-21.

21. Ioris, A. The limits of integrated water resources management : a case study of Brazil's Paraíba do Sul River Basin. Sustainability: Science, Practice, E Policy 2008, 4, 4-11.

22. Amma, N.; Gupta, J. Reconciling IWRM and water delivery in Ghana - The potential and the challenges. Physics and Chemistry of the Earth 2012, 47-48, 33-45; doi: 10.1016/j.pce.2011.06.010.

23. Reta H.; Degefa T.; Getnet, A. Water institutions in the Awash basin of Ethiopia: the Discrepancies between Rhetoric and Realities, The Intl. J. River Basin Management. 2018, 16: 107-121; doi: 10.1080/15715124.2017.1387126.

24. Boelens, R.; Seemann, M. Forced Engagements: Water Security and Local Rights Formalization in Yanque, Colca Valley, Peru. Human Organization 2014, 73 (1), 1-12.

25. Ministry of Water Resources (MoWR). Ethiopian Water Resources Management Policy. FDRE: Addis Ababa, Ethiopia, 1999.

26. Zinzani,A.; Bichsel, C. IWRM and the Politics of Scale: Rescaling Water Governance in Uzbekistan. Water 2018, 10, 281; doi:10.3390/w10030281

27. Jønch-clausen, T.; Fugl, J. Firming up the Conceptual Basis of Integrated Water Resources Management. Water Resour. Dev. 2001, 17, 501-10; doi: 10.1080/07900620120094055.

28. Julien, H. Content Analysis in the Sage Encyclopedia of Qualitative Research Methods. Given, L.M. (ed), SAGE Publications: Thousand Oaks, CA, 2008; pp. 121-23.

29. Ventana Systems, Inc. Vensim Version 7.2. Harvard: USA, 2017. Available at: http://www.vensim.com/documentation (Accessed on 29 January 2018).

30. Creswell, J. W. Research design: Qualitative, quantitative, and mixed method approaches. th $^{\text {th }}$ ed. SAGE Publications, Inc: USA, 2014, ISBN: 978-1-4522-2610-1.

31. Desai, V. and Potter, R.B (Eds). Doing Development Research. SAGE Publications Ltd: London, UK, 2006, p.324, ISBN: 139781412902854

32. Saravanan, V. S.; McDonald G.T.; Mollinga, P.P. Critical review of Integrated Water Resources Management: Moving beyond polarised discourse. Natural Resources Forum 2009, 33, 76-86.

33. World Health Organization (WHO); United Nations Children's Fund (UNICEF) Joint Monitoring Program. Global Water Supply \& Sanitation Assessment Report. WHO/UNICEF: Switzerland/USA, Geneva/New York, 2014, ISBN: 972-924-1503297

34. Carr, C.J. River Basin Development and Human Rights in Eastern Africa-A Policy Crossroads. Springer International Publishing: , Geneva, Switzerland, 2017; p.240, ISBN 978-3-319-50468-1

35. Food and Agriculture Organization (FAO).Coping with Water Scarcity, the Role of Agriculture: Developing a Water Audit for Awash River Basin. A Synthesis report GCP/INT/072/ITA. FAO: Addis Ababa, Ethiopia, 2013; p.46.

36. Savenije, H.H.G.; Hoekstra, A.Y.(Eds.) Water Resources Management. Encyclopedia of Life Support systems: Elolss Publisher Co.Ltd: Oxford, UK, Volume I, 2009.

37. Jiang, M. Towards Tradable Water Rights: Water Law and Policy Reform in China. Global Issues in Water Policy. Springer International Publishing: Geneva, Switzerland, 2017; Volume 18, p.242, ISBN: 978-3-319-67085-0

38. Ingram, H.M., Mann. D.E.; Weatherford, G.D.; Cortner, H.J. Guidelines for Improved Institutional Analysis in Water Resources Planning.Water Resour. Res. 1984, 20, 323-34.

39. Addis Ababa Water Sewerage Authority (AAWSA).Business Plan 2011 - 2020, City Government of Addis Ababa, Ethiopia, 2011. 
40. Reta H.; Degefa, T.; Getnet, A. Water security: stakeholders' arena in the Awash River Basin of Ethiopia. Sustain. Water Resour. Manag.( in Press); doi: 10.1007/s40899-017-0208-2.

41. Hassen, Y.K. Assessment of small-scale irrigation using comparative performance indicators on two selected schemes in upper Awash River Valley. M.Sc, Alemaya University, Dire Dawa, Ethiopia, 2004.

42. Otero, I.; Kallis, G.; Aguilar, R., Ruiz, V. Water Scarcity, Social Power and the Production of an Elite Suburb: The Political Ecology of Water in Matadepera, Catalonia. Ecological Economics 2011, 70, 1297-1308; doi: 10.1016/j.ecolecon.2009.09.011.

43. Saleth, R.M.; Dinar, A. Of Institutional Economics : Linkages within Institutional Structure: An Empirical Analysis of Water Institutions. Journal of Institutional Economics 2008, 4, 375-401; doi: 10.1017/S1744137408001136.

44. Joy, J. K.; Paranjape, S. Multi-Stakeholder Platforms (MSPs) in Water Resources Management: Some Issues and Suggestions. Bangalore, India, 2002.

45. Ostrom, E. Do Institutions for Collective Action Evolve? J. Bioecon. 2013; doi: 10.1007/s10818-013-9154-8.

46. Saleth, R. M.; and Dinar, A. The Institutional Economics of Water: A Cross-Country Analysis of Institutions and Performance. The World Bank/ Edward Elgar: Washington, DC/ Massachusetts, USA, 2004, p.398

47. Petersen-perlman, J.D.; Veilleux,J.C.; Zentner, M.; Wolf, A.T. Complexity and the Role of Institutions." Journal of Contemporary Water Research E Education 2012, 149, 4-12.

48. Warner, J.; Wester, P.; Bolding, A. Going with the flow: river basins as the natural units for water management? Water Policy 2008, 10, 121-138; doi: 10.2166/wp.2008.210. 